\title{
LA MISIÓN ARQUEOLÓGICA ESPAÑOLA EN NUBIA (1960-1966)
}

\author{
The Spanish archaelogical mission in Nubia \\ (1960-1966)
}

\author{
Eduardo Ripoll Perelló ${ }^{1}$
}

Recibido el 15 de abril de 2009. Aceptado el15 de junio de 2009.

Resumen. A raíz de la construcción de la gran pesa de Asuán en los años 60 del pasado siglo, un grupo de entusiastas investigadores españoles participaron en el estudio, documentación y rescate de algunos yacimientos en la zona que se iba a inundar. En este texto se recogen algunas impresiones de uno de los participantes: el profesor Eduardo Ripoll.

Palabras clave: Rescate de monumentos, arqueología, Egipto.

Abstract. As the results of the construction of the great dam of Asuán during the sixties of the past century, a group of enthusiastic Sanish researchers participated in the study, documentation and rescue of some sites in the zone that was going to be covered by the flood. In this text we resume some personal impressions of one of the participants: professor Eduardo Ripoll.

Key Words: Monument rescue, archaeology, Egypt.

Hace unos meses, excavando entre los múltiples papeles, legajos, cajas, archivadores y carpetas de mi padre, en la casa de Barcelona, encontré una serie de documentos que creo que no han sido publicados nunca. La única posible referencia, la he encontrado en su bibliografía en la entrada 153 Salvamento de los monumentos de Nubia, en La Gran Enciclopedia del Mundo, volumen XXI (apéndice), Bilbao, Durvan, S.A. de Ediciones, 1969, cols. 834-840.

Durante el acto de Homenaje al profesor Ripoll, el 30 de abril de 2009, uno de sus dilectos discípulos el Dr. Alberto López Mullor, proyectó durante su intervención un par de imágenes de las campañas nubias de la colección fotográfica del Museu d'Arquèologia de Catalunya. Inmediatamente relacioné estas imágenes con los textos mecanografiados y que transcribo a continuación por su interés historiográfico, documental, sentimental y literario. Se trata de varios documentos independientes, a los que he añadido una breve introducción para contextualizarlos.

\section{INTRODUCCIÓN}

En los años 60 del pasado siglo XX, como consecuencia de la construcción de la gigantesca presa de El Saad el Aali en Asuán, Egipto y Sudán fueron testigos de una serie de circunstancias de gran trascendencia en el valle del Nilo.

La presa de Asuán tendría como efectos positivos proporcionar 20 millones de kilovatios de energía eléctrica a las

(') Este texto ha sido recopilado por Sergio Ripoll, tres años después del fallecimiento del profesor Eduardo Ripoll. 
dos naciones, con una capacidad de agua de 15 millones de metros cúbicos y por otra parte 3 millones de hectáreas de regadío a Egipto.

Como efectos negativos o secundarios se preveía la desaparición en la baja Nubia de numerosos restos arqueológicos y la deportación por un lado de la población sudanesa hacia el sur y por otro, de la egipcia hacia el norte del Nilo. En la zona inundada por el inmenso lago Nasser, al sur de la segunda catarata del río llamada Batn el Haggar o vientre de piedra donde aflora el granito erosionado por la corriente, formando numerosos islotes, el agua alcanzaría la cota de +60 sobre el cauce del río, se extendería unos $500 \mathrm{~km}$ a lo largo del Nilo, con alturas máximas de $100 \mathrm{~km}$ y una media de entre 20-10 kilómetros.

Pero antes del inicio de la inundación prevista para 1966, era necesario rescatar los inmensos yacimientos con sus materiales y los suntuosos monumentos, lo que dio lugar a unas investigaciones intensas y sin precedentes en la historia. La presa se concluyó totalmente el 21 de julio de 1970.

La zona de Nubia se extiende por el Nilo medio desde la primera catarata de Asuán hasta la quinta, dividida en dos regiones la baja Nubia y la alta Nubia también conocida como el país de Kush, que se extiende desde la segunda catarata hasta Meroe.

Para paliar los efectos negativos de la construcción sobre los monumentos y yacimientos arqueológicos de la baja Nubia egipcia y sudanesa, la UNESCO en 1959, a través del profesor Vittorino Veronese, lanzó una angustiosa Ilamada de socorro invitando a todos los organismos arqueológicos competentes del mundo, estados, universidades, institutos, museos, a participar en el salvamento y rescate de Los tesoros arqueológicos de Nubia, ofreciendo atractivas ventajas de donar la mitad de los materiales arqueológicos muebles, e incluso inmuebles, como templos inundables, a las naciones participantes.

Dicho organismo internacional invitó a los estados miembros a participar en dicha tarea y por su parte los gobiernos del Sudán y Egipto ofrecieron a dichos países una parte de los materiales que fueron recuperados. En España el Ministerio de Asuntos Exteriores constituyó un "Comité Español para el salvamento de los tesoros de Nubia" presidido por el excelentísimo señor don Alberto Martín Artajo y del que formaban parte diversos diplomáticos y arqueólogos. La dirección y coordinación del trabajo propiamente arqueológico fue confiada al profesor Martín Almagro Basch. Por parte de los gobiernos del Sudán y de Egipto se concedieron a España varios territorios que fueron explorados a lo largo de las campañas de los inviernos de 1960/61 y 1962/63. Cada una de dichas concesiones tuvo un director técnico: la de Masmas (Egipto) fue dirigida por el profesor Eduardo Ripoll, la de Argin (Sudán) fue dirigida por el profesor Manuel PeIlicer y la de Abkanarti (Sudán) por el profesor Francisco Presedo. Con ellos colaboraron arqueólogos y técnicos de diferentes universidades españolas y también becarios de la Diputación Provincial de Barcelona. Los principales resultados de estos trabajos, fueron el acopio de una gran cantidad de materiales que en su mayor parte fueron entregados por los gobiernos sudanés y egipcio al gobierno español.

La trascendencia que tuvo la intervención española en Nubia, marcó un punto de inflexión en la egiptología española. Las seis campañas que se sucedieron entre 1960 y 1966 tanto en la Nubia egipcia como en la sudanesa tuvieron como recompensa la entrega de una gran parte de los materiales arqueológicos recuperados, que vinieron a enriquecer las colecciones del Museo Arqueológico Nacional ; la concesión de una misión estable en Heraclépolis Magna, que ha garantizado la presencia española en Egipto y ha supuesto una excelente escuela para la formación de muchos arqueólogos y egiptólogos que aún están en activo, y sobre todo, la donación del Templo de Debod, una de las joyas de nuestro patrimonio que se ha llegado a convertir en un emblema de la ciudad de Madrid. Egipto donó cuatro de los templos salvados a distintas naciones colaboradoras: Dendur a los Estados Unidos (se encuentra actualmente en el Metropolitan Museum de Nueva York), Ellesiya a Italia, Taffa a Holanda y el ya mencionado de Debod a España.

Las tareas de excavación del yacimiento donde se localizaba el templo de Debod no fueron llevadas a cabo directamente por la Misión española, sino por el Servicio de Antigüedades de Egipto y una Misión Arqueológica polaca. La Unesco encargó el trabajo de copiar todas las inscripciones de este templo a los egiptólogos F. Daumas y Ph. Derchain. Una vez desmontado el templo en 1961, fue trasladado a la isla Elefantina y allí se conservaron la mayoría de los bloques de piedra hasta la primavera de 1970, siendo trasladados posteriormente a Alejandría. El día 6 de junio de dicho año, fueron embarcados en el buque Benisa y llegaron al puerto de Valencia el día 18 de ese mismo mes. Desde Valencia fueron transportados en camiones hasta Madrid, donde se almacenaron en el solar del Cuartel de la Montaña.

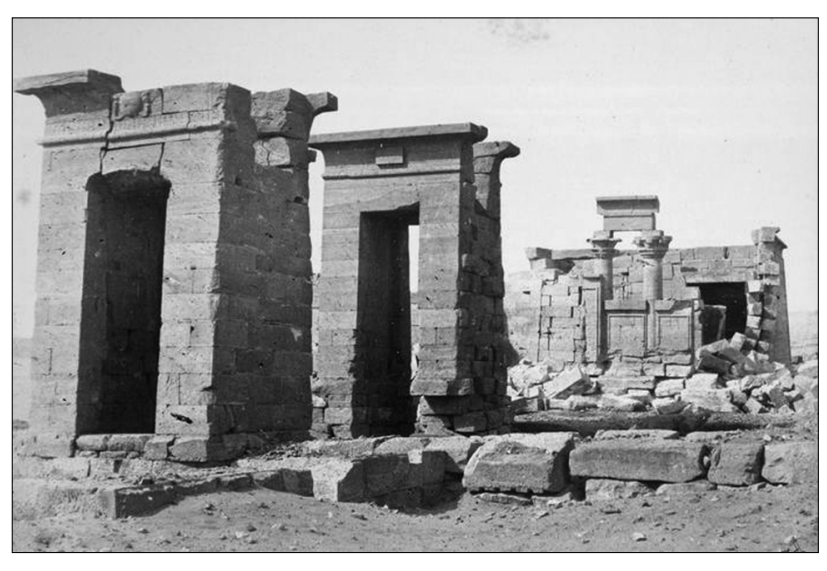

A Figura 1. Vista del templo de Debod en su emplazamiento original. 
La labor de los investigadores españoles fue difícil, pues el Servicio de Antigüedades de Egipto sólo entregó un plano y un croquis del alzado del monumento, junto con algunas fotografias sin ninguna referencia. Muchos bloques habian perdido la numeración y muchos fragmentos llevaban una marca que no correspondía al plano.

\section{HACIA EL SUR}

En el segundo dia de viaje el "Cheik el Beled" -el alcalde del pueblo- dobló la gran curva de Korosko y fue dejando atrás los farallones de sus orillas sobre las que asoman las blancas fachadas de las casas nubias con aspecto de fortaleza. Con el cambio de rumbo, tras un día mas de navegación, la nave nos llevaría a nuestro destino. Arriba, encima de nosotros, trazaba su geometría Orión y más abajo, a nuestra izquierda sobre el horizonte, lucía magnífica la Cruz del Sur señalando el camino del África negra.

El lector se habrá preguntado el por qué del nombre de nuestro barco. El "Cheik el Beled" es el mejor de los varios

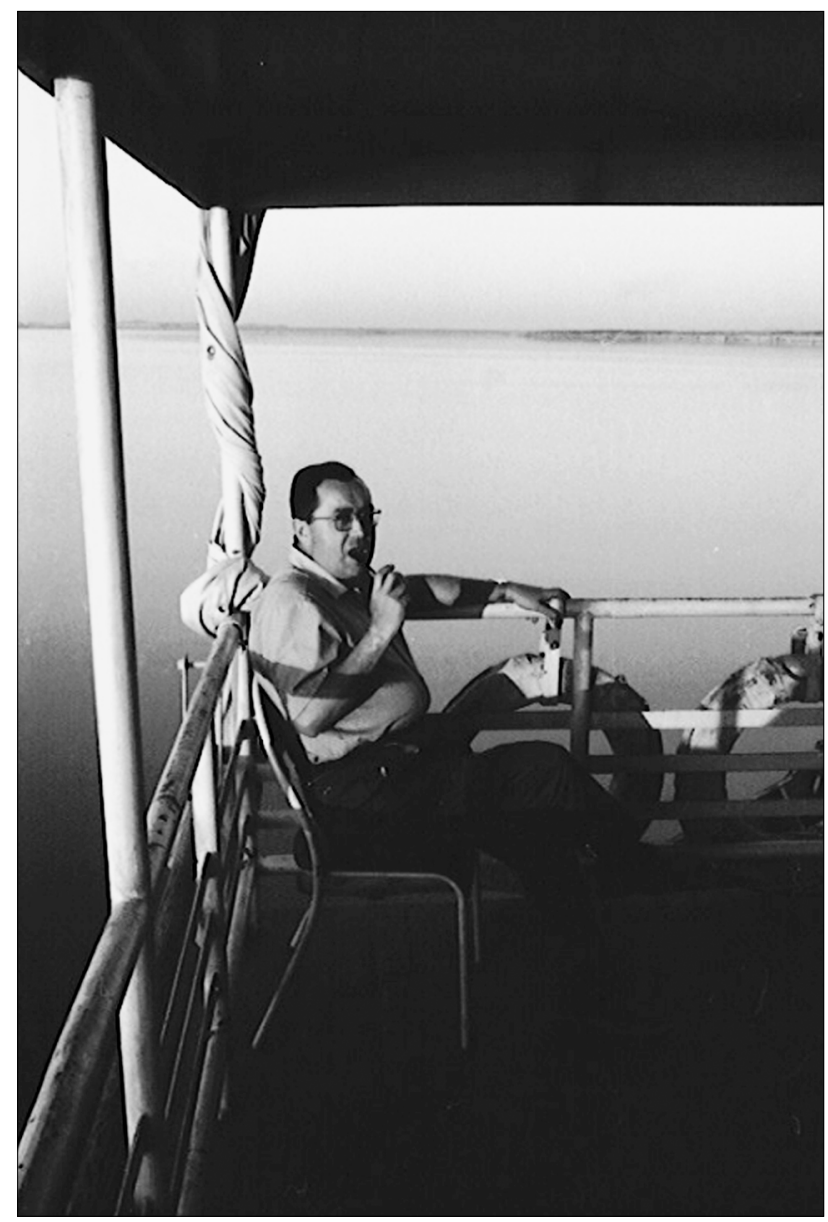

A Figura 2. Eduardo Ripoll a bordo del Cheik el Beled, rumbo a Masmas. (Foto archivo Museu d'Arquèologia de Catalunya.) que componen la flotilla perteneciente al Servicio de Antigüedades del gobierno egipcio y se le bautizó así en homenaje a la magnifica escultura de madera que figura en el Museo del Cairo, encontrada en el siglo XIX por Mariette y que lleva la misma denominación. Camarotes confortables, salón comedor, salón de trabajo e incluso un pequeño laboratorio fotográfico, eran las comodidades de que disfrutaba la misión arqueológica española que viajaba en dirección Sur para hacerse cargo de su concesión de Masmas.

Iba a bordo el equipo de "cuftis" y la impedimenta de la expedición compuesta de instrumentos de trabajo, tiendas de campaña, ropas de abrigo y alimentos. Todo ello reunido con previsión insegura, pues en realidad la información que teníamos de la zona asignada era muy escasa: un lugar de extensión indeterminada entre Aniba y Abu Simbel que ni siquiera estaba señalado en los mapas y la noticia de que tendríamos por vecinos a los arqueólogos de las misiones inglesa de Cambridge, egipcia de la Universidad del Cairo y americana de la Universidad de California.

Al día siguiente, después de parar en Aniba, un diminuto centro administrativo egipcio, costeamos a lo largo de una faja de desierto y cuando de nuevo alcanzamos los palmerales ya estábamos en Masmas. Un poste de hierro con la indicación "Masmas" en árabe y un farol colgado que se enciende una vez por semana para orientar al pequeño barco correo. Detrás, unas casas amplias alineadas en el mismo sentido del río, y muy pronto, gente muy amable. Característicos ejemplos de la raza nubia, ofreciéndose para ayudarnos.

La instalación en dos casas nubias, relativamente confortables, la contratación del personal y el reconocimiento de una pequeña zona para empezar el trabajo fueron cuestión de cuarenta y ocho horas. A partir de ese momento la misión trabajaba como si hiciera años que estuviera allí.

\section{DESENTRAÑANDO EL PASADO}

El trabajo del arqueólogo no es una labor puramente de azar. La Arqueología es una ciencia. Como tal, tiene unos postulados, unos principios, por los que se rige, y sobre todo unos métodos, gracias a los cuales puede obtener de una simple piedra, de un fragmento de una vasija, o simplemente de la disposición de una capa de tierra, datos de gran importancia para el conocimiento de la vida, costumbres, economía, ideas, en una palabra, construir la historia de los pueblos y culturas que dejaron en la faz de la tierra unas huellas materiales de su paso, que no ha podido borrar el transcurso de los milenios.

Sobre la base de una meticulosa observación de los indicios que se presentan a sus ojos, el arqueólogo puede formularse una hipótesis de trabajo, que se tratará de confirmar o destruir con los nuevos descubrimientos. 
Muchas veces un pequeño fragmento de un cacharro de cerámica, de un tipo bien conocido por otras excavaciones, permite dar una fecha aproximada a una tumba o a una vivienda. Resulta en este aspecto curioso destacar que, desde el punto de vista estrictamente científico, es por lo general más interesante el hallazgo de un cacharro de cerámica que una joya de oro, por ejemplo. La razón de ser de esto es muy sencilla; un cacharro de cerámica tiene una vida limitada, se rompe pronto, y por esta misma razón los gustos de la gente por las formas de las cerámicas cambian constantemente ante la necesidad de reponer las vajillas rotas. Una joya en un metal precioso es una pieza naturalmente muy apreciada, que puede pasar de padres a hijos durante muchas generaciones, y que es preservada de toda pérdida o rotura. Ello motiva el que cuando una joya aparezca en una tumba podemos pensar que dicho objeto fue fabricado muchas generaciones antes de que se realizara el enterramiento, y por lo tanto que la fecha de la joya no sea la misma que la del individuo que está alli enterrado.

Este es tan sólo un ejemplo que pone de manifiesto uno de los postulados de los que el arqueólogo debe servirse para desentrañar el pasado.

\section{ABU-SIMBEL Y OTROS MONUMENTOS NUBIOS}

El más conocido de los templos faraónicos de Nubia es el de Abu-Simbel, situado en la orilla occidental. Las cuatro colosales estatuas de Ramsés II que franquean la entrada del templo se ven desde lejos y dominan un gran trecho del río. El conjunto fue hecho tallar por dicho faraón para dedicarlo a Re-Harakhti, dios del sol naciente que era su dios personal y con el que el pueblo le identificaba. A esta divinidad se la ve en un nicho encima de la puerta de entrada para que pueda ser el primero que contemple la salida del sol con sus ojos de halcón. El faraón está también representado bajo la forma de Osiris en las ocho gigantescas estatuas del interior y su imagen en diferentes momentos de su existencia se multiplica en las paredes del templo. Una de las características mas notables de este monumento, poco divulgada, es que en ciertas épocas del año los rayos del sol naciente, siguiendo el eje exacto del conjunto, acarician las cuatro estatuas de divinidades sentadas en el santuario que representan a Re-Harakhti, Ramsés II, Amón-Re y Ptah.

A unos 100 metros hacia el Norte se encuentra otro templo rupestre, más pequeño, dedicado a la diosa Hator y a Nefertari, la esposa del rey. La fachada, adornada con seis estatuas da acceso a un interior con columnas hatóricas con todas la paredes Ilenas de representaciones de la vida regia en relación con las divinidades, todo de carácter más delicado que el templo grande.

Este es el conjunto de Abu-Simbel cuya salvación se ha ido tejiendo y destejiendo a lo largo de tres años, con in- tervención de la prensa de todo el mundo. ¿Se salvará AbuSimbel? ¿Se llevará a la práctica el proyecto italiano de levantamiento del conjunto por encima del futuro nivel de las aguas? Cuando aparezcan la siguientes líneas faltarán muy pocos días para el 1 de abril, último plazo puesto por el gobierno egipcio para que se inicien los trabajos. En estos momentos la impresión acerca de la realización del proyecto es más bien pesimista. Si antes de aquella fecha la UNESCO no ha reunido los sesenta millones de dólares que costará la operación de salvamento, habrá que renunciar a la misma.

Nunca en la historia de la ciencia arqueológica se había producido la coyuntura que ha acontecido en Nubia. En una región de límites muy concretos se han dado cita arqueólogos de diversos países, para desarrollar la labor, planeada previamente, del salvamento de todos los vestigios de interés arqueológico o monumental, que en otro caso hubieran quedado sepultados bajo las aguas del Nilo represadas por la nueva presa de Asuán.

El trabajo más costoso y espectacular de los que se están llevando a cabo en Nubia es, sin duda, el del traslado a lugar seguro de los monumentos que ofrezcan algún interés artístico.

Pero, además de Abu-Simbel existen en Nubia muchos restos arqueológicos y monumentos que han merecido la atención de los arqueólogos. Para su salvación los servicios competentes de la UNESCO y el gobierno egipcio los clasificaron en orden de importancia y de posibilidades de trabajo teniendo en cuenta las ofertas de colaboración de diferentes naciones entre las cuales se contaba España. De primera importancia se consideraron los templos excavados en la roca o construídos al aire libre, en número de dieciocho: unos Beit-el-Uali, Gerf Hussein, Uadi Sebua, Amada, Derr, Ellesiya, Au-Oda y los dos de Abu-Simbel- corresponden al Imperio Nuevo, otros -Piale, Bigga, Dabud, Kertassi, Taffa, Kalabcha, Dendur, Dakka y Meharraka- son de época grecorromana. Algunos de estos templos fueron transformados en iglesias en época cristiana y guardan huellas de esta transformación bajo la forma de inscripciones, pinturas, etc.

Asimismo se encuentran en Nubia vestigios de fortalezas y de ciudadelas que fueron construidas para proteger las rutas comerciales y para mantener el orden y la paz en el país. Entre ellas hay que citar la de época bizantina de Cheik Daud, excavada por la misión española, y muy especialmente la gigantesca de Kars Ibrim, la Primis de los romanos, donde tuvo su guarnición el general Petronio y que estuvo en funciones hasta un momento muy avanzado del silo XIX bajo los turcos que mantuvieron alli durante siglos un regimiento bosnio. Pero todos estos yacimientos están estrechamente relcionados formando un conjunto arqueológico colosal, asi por ejemplo, en los grandes frisos rocosos del pie de la montaña donde se asienta Kars Ibrim existen algunos de los mejores conjuntos de grabados rupestres de toda Nubia. 


\section{LA VIDA EN TORNO AL NILO}

Nubia, tras su apariencia de tierra desolada, oculta una fauna riquísima, con la que inevitablemente se entra en contacto al vivir allí. El Nilo es el centro de la vida animal de este país; en el interior del desierto, más allá de la montañas desaparecen por completo los vivientes. El implacable avance de la civilización ha ido haciendo retroceder la fauna, en especial los grandes animales, que han vuelto a refugiarse en la profundidades del Nilo Blanco y del Nilo Azul, en la zona propiamente ecuatorial.

En tiempos prehistóricos Nubia estaba poblada por elefantes, jirafas, y otros grandes mamíferos, que aparecen representados en los grabados rupestres que existen en los paisajes rocosos de la orilla del río y especialmente en nuestra zona de Masmas. Los bajorrelieves polícromos de época faraónica dan constancia de la presencia de grandes hipopótamos, especie que actualmente no puede hallarse, y aún de forma escasa, más que al Sur de Khartum.

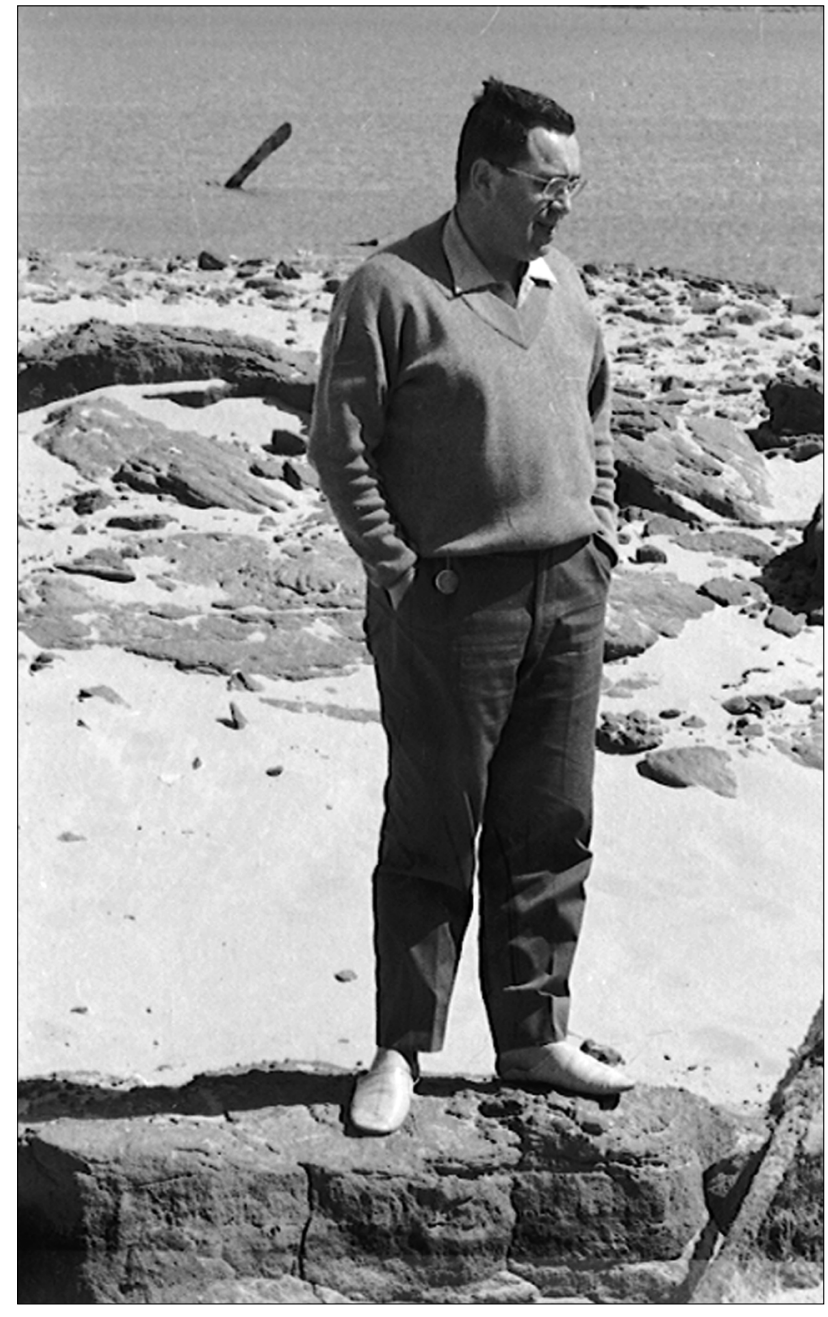

A FiguRA 3. Eduardo Ripoll conrolando las tareas de excavación en Masmas. (Foto arhivo Museu d'Arquèologia de Catalunya.)
Las variantes de animales que hoy en día pueden verse en la alta y la baja Nubia, fueron también meticulosamente dibujadas por los artistas de época faraónica. En los atardeceres del río componen una estampa habitual las bandadas de ánades y patos silvestres, que no muestran recelo ante la presencia del hombre, ya que nadie los persigue. Menos confiados son los cocodrilos que, conociendo los parajes que frecuentan, pueden verse sobre todo en la segunda catarata. Los nubios no desaprovechan ninguna ocasión que se les presenta de matar esta especie de saurios, con armas de fuego o pequeñas bombas de mano de fabricación artesana. La huella del cocodrilo puede ser confundida en algunos casos con la del gigantesco lagarto, de hasta dos metros de longitud, que los indígenas denominan "waran". Es un animal acuático, como el cocodrilo, pero se diferencia de aquel en que su cuerpo no se halla protegido por gruesas escamas, y posee una agilidad enorme que le permite encaramarse a los altos peñascos y zambullirse desde alli al río, en espectaculares saltos. Para quien no se halle habituado a ello puede constituir una fuerte emoción encontrar uno de estos reptiles a escasa distancia.

En las noches nubias, bajo un cielo limpísimo cubierto materialmente de constelaciones, puede oírse la desagradable risa de la hiena y el ladrido del chacal que se acercan al río en busca de carroña.

Al estar en cotidiano contacto con la tierra, en el desempeño de nuestra labor arqueológica, hemos conocido muy de cerca el oscuro mundo de los pequeños animales terrícolas. Las zonas del desierto rocoso que están próximas al Nilo, ocultan en sus quebraduras multitud de escorpiones verdiamarillos de gran tamaño, por los que los nubios, siempre descalzos, muestran una sorprendente despreocupación. Cuando alguno de estos arácnidos hacía su aparición era inmediatamente desprovisto de la cola donde se aloja la uña ponzoñosa, y enseñado a todos entre gran regocijo.

Entre las arenas se oculta una variedad de arañas peludas de gran tamaño, blancuzcas y ciegas, que poseen un aguijón venenoso, tambien pueden hallarse diversas variedades de grandes coleópteros que, al caminar trazan en el suelo una característica huella.

Las serpientes tampoco faltan en esta tierra. A menudo en manos de encantadores que las pasean por los lugares de afluencia turística desprovistas por completo de esa electrizante sensación que provocan en libertad.

\section{EL GUARDIÁN DE LA TUMBA}

El pozo que franqueaba la entrada de aquella tumba descendía verticalmente entre las paredes de la roca. Uno de nuestros obreros "cuftis", verdaderos especialistas en Arqueología, se deslizó en el interior, dispuesto a comenzar a cargar de tierra las espuertas de esparto que desde arriba le iban bajando, e ir dejando practicable el orificio que daba 
paso al enterramiento. Todas las apariencias nos hacian creer que se trataba de una tumba faraónica correspondiente a la XVIII dinastía. Pronto el fondo del foso quedó lo suficientemente libre de escombros y tres obreros nubios pudieron descender a él, para acelerar el trabajo. Nosotros, en la superficie, vigilábamos la delicada operación del cribado de toda la tierra que se extraía, para que no se nos escapara ni el más pequeño objeto.

La normalidad del trabajo viose de repente truncada por unos gritos que partían del interior de dicho pozo:

-iTaabán, Taabáni (iUna serpiente, una serpientej)

Tres de los cuatro hombres aparecieron jadeantes por la boca del pozo, tras una rápida ascensión por el tronco de palmera que hacia la veces de escalera, gesticulando y hablando a demasiada velocidad para que pudieramos entenderlos. Mansur seguía abajo. Transcurrieron los segundos y por fin su cara surgió, demudada, de las profundidades de la tumba, y sin pararse a dar explicaciones inició una rápida carrera hasta el Nilo, que se hallaba a unos cien metros, para enjuagarse con agua. El trabajo quedó interrumpido para dar paso a una serie de excitadas explicaciones. Lentamente logramos entender lo que sucedía. En la cámara donde debía estar el enterramiento se alojaba un áspid, que había caído al interior del pozo y no había podido volver a salir.

El terror supersticioso cundió entre nuestros obreros nubios y "cuftis". Aquella serpiente era el guardián de la tumba contra todo aquel que intentara profanarla, por eso habia escupido veneno al rostro de Mansur, a modo de aviso. Pero Mansur era un valiente y no creía en supersticiones; cogió su azada y, lentamente, sabiendo a lo que se exponía, empezó a descender por el tronco de palmera. El áspid ya le esperaba. La lucha fue corta, el áspid, herido, rebotaba entre las paredes del pozo mientras el nubio seguía descargando golpes con la azada, hasta que el reptil quedó inmóvil del todo.

\section{EL ROBO A LOS MUERTOS}

El desierto Nubio es un inmenso cementerio. Los enterramientos se suceden, uno junto a otro, durante kilómetros, en ingente acumulación de culturas. La conservación de las tumbas es magnífica, dado el que en esta tierra no ha habido cultivos ni edificaciones que pudieran haberlos destruido. Por otra parte la sequedad del desierto preserva de la descomposición y pérdida de las materias orgánicas, lo que, para el arqueólogo, resulta de gran interés. Los cadáveres, las ofrendas, los tejidos, la madera, aparecen de forma casi milagrosa, después de milenios de permanecer en la oscuridad de la tierra. Por el contrario, destruyendo este benéfico y protector efecto del clima aparece el ladrón de tumbas.

Los cementerios anteriores a la época cristiana contienen, en su mayoría, objetos que en todas las épocas han sido muy cotizados. No es raro el hallazgo de metales preciosos, piedras duras, y otras piezas que tienen un valor, incluso despreciando su interés artístico o arqueológico. Ello ha dado lugar a la existencia de una verdadera clase social de saqueadores de tumbas.

La violación de los cementerios ha existido desde tiempo inmemorial. A menudo las tumbas son saqueadas muy pocos años después de realizada la inhumación, si el enterramiento no ha quedado bien disimulado. En otros casos la violación data de doscientos o trescientos años, aunque en determinado tipo de tumbas ésta es mucho más reciente o incluso actual. El ladrón de tumbas es un ser superdotado y especializado, es un arqueólogo autodidacta en parte. Posee una ciencia empírica que le permite detectar el lugar donde existe una tumba con absoluta certeza, y saber de antemano si alguno de sus colegas la ha visitado ya y, si por lo tanto vale la pena de introducirse en ella.

Los ladrones de tumbas se agrupan en aldeas, totalmente dedicadas a este tipo de trabajo, en las que las enseñanzas de tipo práctico se transmiten de padres a hijos, y así de generación en generación.

A pesar de la riqueza arqueológica de Nubia, el trabajo de generaciones de saqueadores ha hecho que actualmente sea muy raro el hallazgo de una tumba intacta. No obstante el ladrón es un hombre respetuoso, hasta cierto punto, con los muertos, que se limita a tomar únicamente los objetos de metal precioso y trabaja con tal delicadeza, que en la mayoría de los casos, no rompe ni uno sólo de los frágiles vasos cerámicos que componen los ajuares de los muertos. Sin embargo las trazas del paso del ladrón quedan en la tumba. El arqueólogo encuentra a veces la cuerda que aquel utilizó para introducirse en el pozo, otras veces es un instrumento que se melló y fue abandonado por inservible, o una prenda de vestir. En otros casos el ladrón no entra en la tumba por el pozo que le daba acceso originariamente, sino que excava un nuevo pozo que penetra en línea recta a la cámara donde se encuentra el enterramiento. El arqueólogo encuentra también huellas de este trabajo que el saqueador realiza con especial maestría, sin errar el golpe, y que asombra por la cantidad de conocimientos sobre el terreno y el tipo de tumba que revela. Muy a menudo debemos descubrirnos ante verdaderas maravillas en este delicado trabajo del robo de los muertos, y hemos pensado muchas veces que sería estupendo tener entre nuestros obreros algunos auténticos ladrones de tumbas.

\section{CUFTIS}

El trabajo arqueológico se realiza en Nubia con dos tipos de obreros; los nubios y los "Cuftis". La palabra "cufti" quiere decir procedente de Cuft, una pequeña aldea cercana a Kena, al norte de Asuán.

Cuft era un importante núcleo de ladrones de tumbas, algo así como un centro de estudios superiores donde se 
aprendía lo más difícil y delicado de la técnica del expolio a los muertos. De alli salian los maestros, que eran los que acometían con éxito empresas de mayor envergadura. Desde hace tiempo las cosas han cambiado y actualmente la justicia persigue de forma implacable a todo aquel que intente saquear el tesoro arqueológico del país, lo que ha obligado a los descendientes de aquellos novelescos ladrones a cambiar de oficio. Sin embargo para todo aquel que entra en contacto con la arqueología... aunque sea en calidad de ladrón, resulta muy difícil desvincularse de ella, y ahora los exladrones trabajan al lado de la ciencia como obreros especializados ("cuftis") en las empresas arqueológicas. El Servicio de Antigüedades de Egipto regula además su preparación, sometiéndolos a una serie de pruebas prácticas sobre el terreno que acreditan la valía del operario. Los "cuftis" forman una verdadera casta, casi todos se hallan emparentados entre sí, lo que en el mundo islámico tiene gran importancia, son considerados con gran respeto por sus conciudadanos, y sobre todo tienen un pundonor profesional extraordinario, como lo acredita el siguiente episodio:

Nos hallábamos excavando una serie de pequeñas tumbas en adobe en forma de mastaba, que presentaban una pequeña cámara funeraria donde era inhumado el difunto con un ajuar compuesto principalmente de unas bellas cerámicas policromas. La cámara se hallaba, en general, repleta de la fina arena del desierto, lo que había protegido de forma extraordinaria las vasijas. En cierta ocasión un "cufti" tuvo la mala fortuna de poner el pié encima del lugar donde estaba enterrado un finísimo cuenco decorado que se rompió al sufrir la presión del peso de obrero. Inmediatamente el "cufti" ensució con tierra los bordes de la fractura de la vasija para hacer creer así que se trataba de una pieza rota desde antiguo. Cuando el cuenco salió a la luz, le hicimos notar que trabajara con cuidado para que no se rompieran más piezas. El resultado de esta pequeña observación fue tremendo; el "cufti" rompió a llorar amargamente, como un niño pillado en falta, y creyéndose despedido del trabajo se disponía a emprender el largo viaje de retorno a Cuft.

El "cufti" trabaja intensamente durante toda la jornada y además lo hace con cariño, porque su trabajo le apasiona y si no pudiera estar en contacto cotidiano con las cosas antiguas, como ellos mismos dicen, preferiría no trabajar. Quede aquí nuestro agradecimiento a los "cuftis" sin los que sería muy difícil llevar a cabo trabajos arqueológicos de envergadura en Nubia.

\section{ESCRITO DIRIGIDO AL PRESIDENTE DE LA DIPUTACIÓN PROVINCIAL}

Como es sabido al Ilamamiento lanzado por la UNESCO para salvar los monumentos arqueológicos de Nubia amena- zados por las aguas de la gran presa de Asuán, respondieron buen número de países y entre ellos España. Nuestro país ha realizado tres campañas de salvamento de tesoros arqueológicos en aquella lejana región con frutos óptimos de los que se ha ocupado relativamente la prensa. Además de aumentar el prestigio nacional en muchos aspectos, estas actividades enriquecerán los Museos arqueológicos españoles, ya que tanto el gobierno egipcio como el del Sudán entregan a los países participantes la mayor parte de los materiales recogidos.

En la campaña de este año (1963) ha estado presente la Diputación Provincial de Barcelona, pues aunque no ha intervenido directamente en la organización y financiación de las campañas efectuadas, ha enviado a sus arqueólogos para que contribuyeran a la realización de las mismas. De los ocho especialistas españoles que han trabajado en Egipto y en el Sudán durante este invierno, cuatro pertenecen a la Diputación Provincial de Barcelona: el director de la Misión Arqueológica de Nubia, profesor Almagro, Director de las excavaciones de Ampurias; el profesor Ripoll, Director del Instituto de Prehistoria y Arqueología de la Diputación Provincial y los becarios de dicho Instituto Sres. Don Luis Monreal y Don Miguel Llongueras.

Nuestros arqueólogos han desarollado sus actividades en la región de Masmas en la Nubia egipcia, habiendo sido nombrado Director de esta concesión el profesor Ripoll. En esta zona, sólo parcialmente excavada durante la presente campaña, se han descubierto cementerios faraónicos de la XVIII dinastía, cristianos y meroíticos. En uno de éstos últimos los materiales encontrados son de gran riqueza. Así mismo se han explorado las áreas de desierto de dicha concesión habiéndose descubierto gran número de grabados rupestres de diferentes épocas que van desde la Edad de Piedra hasta el período copto cristiano. Todos estos materiales se encuentran actualmente en la ciudad de El Cairo pendientes de su entrega definitiva por parte del gobierno egipcio. Se espera que lleguen a España durante el próximo verano (1963). Con ellos y con los obtenidos en las campañas anteriores, el Ministerio de Asuntos Exteriores está organizando una exposición que tendrá lugar en Madrid en el otoño del presente 1963 y que se tiene la confianza de que puedan traer a Barcelona. También cuando dicho Ministerio, en relación con el de Educación Nacional, efectúe el reparto de todos los objetos obtenidos entre los museos arqueológicos españoles, se confía en que el Museo Arqueológico de la Diputación Provincial de Barcelona reciba una buena colección en correspondencia a la contribución de la Corporación Provincial que ha enviado a sus arqueólogos a participar en esta empresa científica internacional de tanta importancia. 